\title{
Efficiency enhancement of Solar Cell by introduction of Cerium Oxide along with Silicon Nitride
}

\author{
U. Gangopadhyay, S. Ray, E. Panda, S. Jana, S. Das \\ Sponsored Research Project Laboratory, Nazirabad, Kolkata-700150, India \\ Meghnad Saha Institute of Technology (TIG), Nazirabad, Kolkata-700150, India
}

Email address:

utpal_ganguly@yahoo.com (U. Gangopadhyay)

\section{To cite this article:}

U. Gangopadhyay, E. Panda, S. Ray, S. Jana, S. Das. Efficiency Enhancement of Solar Cell by Introduction of Cerium Oxide along with Silicon Nitride. International Journal of Renewable and Sustainable Energy. Vol. 2, No. 2, 2013, pp. 46-50.

doi: 10.11648/j.ijrse.20130202.14

\begin{abstract}
In this paper we have carried out the comparative simulations study of $\mathrm{n}$ type c-Si Solar Cell with SiNx and $\mathrm{SiNx}+\mathrm{CeO}_{2}$ layers separately by PC1D simulation software. The motivation of this paper is to determine the optimum condition when Solar Cell yields more efficiency by using $\mathrm{SiNx}+\mathrm{CeO}_{2}$ layer rather than only $\mathrm{SiNx}$ layer respectively on the front side of the Solar Cell. For these purpose the simulations have been done by changing the thickness and refractive index of $\mathrm{CeO}_{2}$ layer. By the observation of simulation's data i.e. reflectance versus wavelength, Quantum Efficiency versus wavelength, and current density versus voltage curves, it has been endeavored to determine the optimum condition when the Solar Cell with $\mathrm{SiN}_{\mathrm{x}}+\mathrm{CeO}_{2}$ layer yield the maximum possible efficiency. In this paper the efficiency of $\mathrm{Si}+\mathrm{SiNx}+\mathrm{CeO}_{2}$ combination has been found as $17.34 \%$ whereas the $\mathrm{Si}+\mathrm{SiNx}$ combination gives the efficiency about $16.91 \%$.
\end{abstract}

Keywords: PC1D; Anti reflection coating(ARC); Quantum Efficiency; Short Circuit Current Density; open circuit voltage

\section{Introduction}

During the last decade, the Photovoltaic industry has demonstrated an annual growth rate of $87 \%$ [1]. With the escalating demands of power supply, and increase in tariff of electricity generation on a per unit basis, there has been an ineluctable need of designing the solar modules in a way that the maximum efficiency is obtained, with the concurrent minimization of the various losses that occur in a photovoltaic cell. The losses that primarily hamper efficiency of a solar cell are optical losses, recombination losses and resistivity losses $[2,3]$.

It has already been reported that bare Silicon gives $40 \%$ reflectance for which we find a low efficiency [4]. To reduce this reflectance an antireflection coating (ARC) coating is being used. Generally in industrial production line $\mathrm{SiNx}$ is extensively used as ARC for $\mathrm{p}$ type Solar Cell [5] because it produces fixed positive charge density of $10^{12}$ at the emitter surface of the $p$ type Solar Cell [4]. But in this paper $\mathrm{n}$ type solar cell is being used. Due to the detrimental effect of application of SiNx film on $n$ type silicon Solar Cell [4] a suitable ARC is necessitated on the front surface of $\mathrm{Si}$ which can produce a fixed negative charge on the emitter surface of $n$ type solar cell.

Generally $\mathrm{CeO}_{2}$ and $\mathrm{Al}_{2} \mathrm{O}_{3}$ are used to overcome the above drawbacks $[6,7]$. In this paper $\mathrm{CeO}_{2}$ has been used. It has already been reported that $\mathrm{CeO}_{2}$ acts as a good antireflection coating and has many superior properties like high dielectric constant, large bandgap $(\sim 6 \mathrm{eV})$, good thermal stability ,a very small lattice mismatch $(\Delta a=0.35 \%)$ and can induces negative charge at the emitter surface of $n$ type Silicon Solar Cell [8].

Through a number of simulations we have attempted to compare and contrast the scenario when efficiency plots for $\mathrm{SiNx}$ layer and $\mathrm{SiNx}+\mathrm{CeO}_{2}$ layer are juxtaposed.

\section{Simulation and Results}

We have carried out all simulation by PC1D simulator in order to determine how the variations between short circuit current and open circuit voltage, reflectance and wavelength, quantum efficiency and wavelength occur by changing of the parameters like refractive index, thickness etc of $\mathrm{CeO}_{2}$ and $\mathrm{SiNx}$ layer. An ideal p-n-n+ Solar Cell have been taken with area $100 \mathrm{~cm}^{2}$. The doping density of base material is $10^{16} \mathrm{~cm}^{-3}$ with thickness is $200 \mu \mathrm{m}$. The $\mathrm{p}$ type emitter has a peak density of $10^{19} \mathrm{~cm}^{-3}$ with thickness 0.5 
um and the $\mathrm{n}+$ rear junction has a peak density of $10^{19} \mathrm{~cm}^{-3}$ with thickness $0.8 \mathrm{um}$. The all over simulation has been carried out for AM 1.5 Global Solar spectrum [4]. The typical $\mathrm{n}$ type c-Si Solar Cell used for the simulation purpose is shown in fig. 1

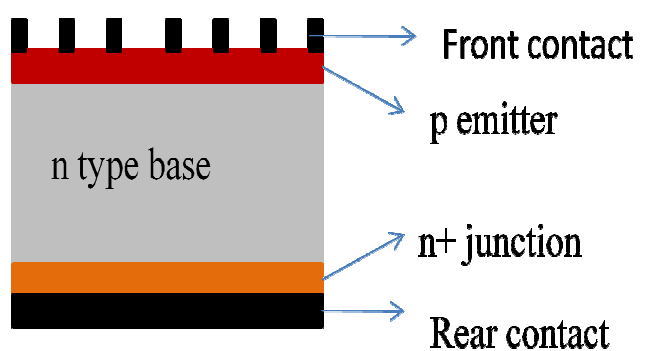

Figure 1. c-Si Solar cell structure used for simulation.

\subsection{With Only Silicon Nitride Upon Silicon Substrate}

In the first stage of our simulation, we have considered only Silicon Nitride at the front surface of silicon substrate [fig.2] as a antireflection coating. Under some specified conditions viz, with $\mathrm{SiNx}$ thickness $=65 \mathrm{~nm}$, SiNx refractive index (r.i.) $=2.00$ we find an efficiency of $16.91 \%$.The characteristic table for the required simulation is shown below. The performance parameter obtained by simulation of the Solar Cell is shown in table 1.

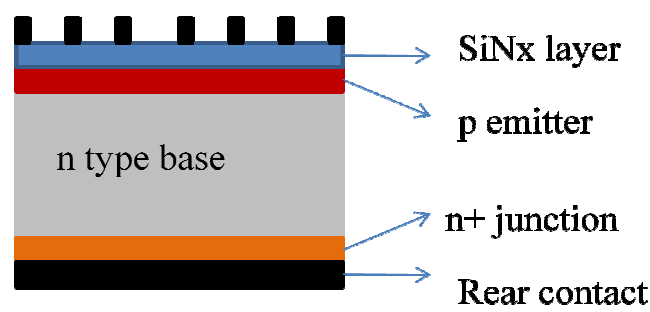

Figure 2. Arrangement of SiNx layer on Si solar cell.

Table 1. Simulated Parameters for crystalline silicon structured with Si+SiNx combination.

\begin{tabular}{ccccc}
\hline $\begin{array}{c}\text { SiNx thickness } \\
(\mathbf{n m})\end{array}$ & SiNx r.i. & $\begin{array}{c}\text { Voc } \\
\text { (V) }\end{array}$ & $\begin{array}{c}\text { Isc } \\
\text { (A) }\end{array}$ & $\begin{array}{c}\text { Efficiency } \\
(\%)\end{array}$ \\
\hline 65 & 2.00 & 0.607 & 3.36 & 16.91 \\
\hline
\end{tabular}

\subsubsection{Variation of Short Circuit Current Density Versus Open Circuit Voltage}

The plot between current density and voltage has been drawn, by keeping the refractive index of SiNx at 2.0, and thickness of $\mathrm{SiNx}$ layer $=65 \mathrm{~nm}$. Open circuit voltage is found to be $0.607 \mathrm{~V}$. The corresponding short circuit current is $3.36 \mathrm{~A}$. It is found that the efficiency in this case is $16.91 \%$ [Fig 3].

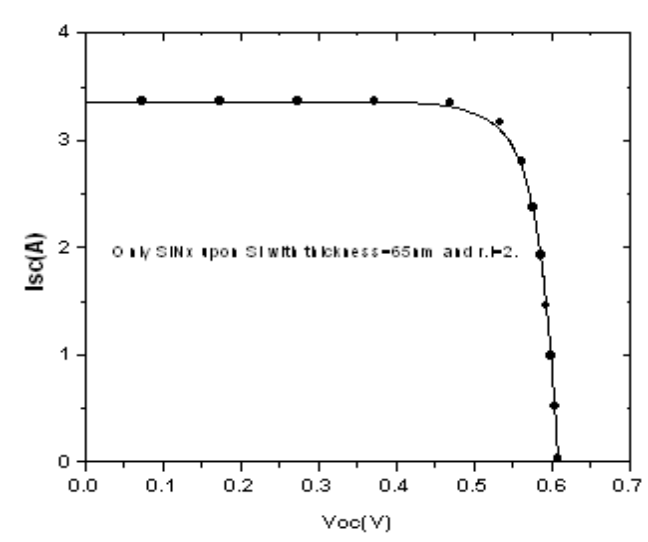

Figure 3. Variation of short circuit current density versus open circuit voltage.

\subsubsection{Variation of Quantum Efficiency Versus Wave- length}

Fig. 4 as depicted below is a plot between quantum efficiency and wavelength of $\mathrm{Si}$ with $\mathrm{SiN}_{\mathrm{x}}$ as antireflection layer, where the refractive index of Silicon Nitride layer has been kept at 2.0, and the thickness of layer has been maintained as $65 \mathrm{~nm}$.

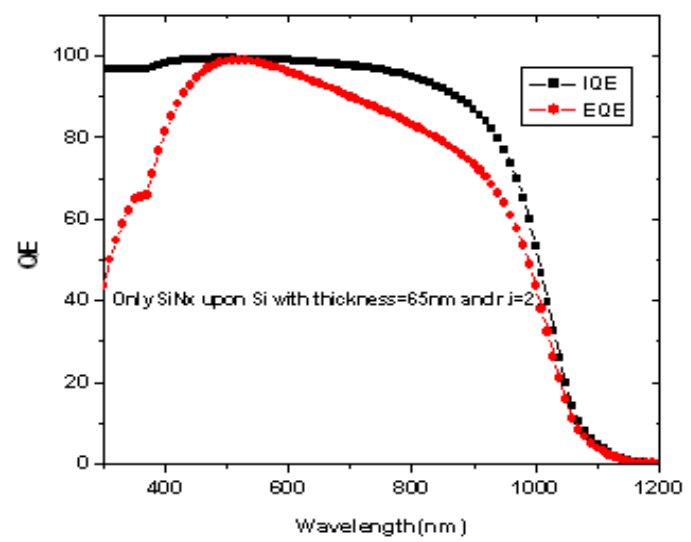

Figure 4. Variation of quantum efficiency versus wavelength with Si+SiNx layer, under stated conditions.

Prior to a detailed elucidation of the quantum efficiencywavelength curve, an illustration of the terms - external and internal quantum efficiency are necessary.

Quantum efficiency is basically a measure of the percentage of photons striking the photo-reactive surface of a device, and consequently produces charge carriers. It is again of two types-

1. Internal Quantum Efficiency

2. External Quantum Efficiency

Internal quantum efficiency is the ratio of the number of charge carriers collected by the solar cell to the number of photons that shine on the solar cell from outside and are absorbed by the cell. Again, external quantum efficiency is defined as the ratio of the number of charge carriers collected by the solar cell to the number of photons of a given energy shining on the solar cell from outside [4]. Both in- 
ternal and external quantum efficiencies have been plotted against wavelength in the range of 300 to $1200 \mathrm{~nm}$. We observe that the curve for Internal Quantum Efficiency has maintained a relatively flat nature in the wavelength range of $300-980 \mathrm{~nm}$, and has retained an efficiency value of about $98 \%$. But, it is also to be noticed, that the External Quantum Efficiency curve has started off with an efficiency value of $40 \%$, and then it is advanced to a peak, where the efficiency value is same as the highest efficiency value attained by the IQE curve, i.e $98 \%$. But it again descends steadily up to an efficiency value of $70 \%$. From the point where wavelength is $950 \mathrm{~nm}$, the EQE curve starts declining abruptly, and ends in attaining a zero value of quantum efficiency, at a wavelength of $1200 \mathrm{~nm}$.

\subsubsection{Variation of Reflectance Versus Wavelength}

As the reflectance of a coated film decreases, the transmission consequently increases. Hence the absorption of photon into the base material rises if and only if the absorption of the coated material is too low. Henceforth, more number of electron-hole pairs are generated at the junction, thereby increasing the generation rate of base material manifold. Therefore, the short circuit current density increases. This is followed by an increase in the efficiency. In this case, an efficiency value of $16.91 \%$ is obtained. At the first place, we are going to take up the reflectance versus wavelength plot, when only $\mathrm{SiNx}$ is used along with the Si substrate. Fig. 5 shows that in the UV region, we are not getting a good response for the transmission through the film. The reason behind this is, that $\mathrm{SiNx}$ does not exhibit appreciable response in the Ultra Violet region. [6] A minimum reflectance is procured at about $500 \mathrm{~nm}$ wavelength. It is to be noted, that in order to improve the transmission to a desirable value, the average reflection has to be brought down to a minimum possible value. This necessitates the introduction of a material that will enable us to accomplish the same. We have thus incorporated Cerium Oxide, a new material, with which we have performed several simulations and have obtained some desirable nature of the curves.

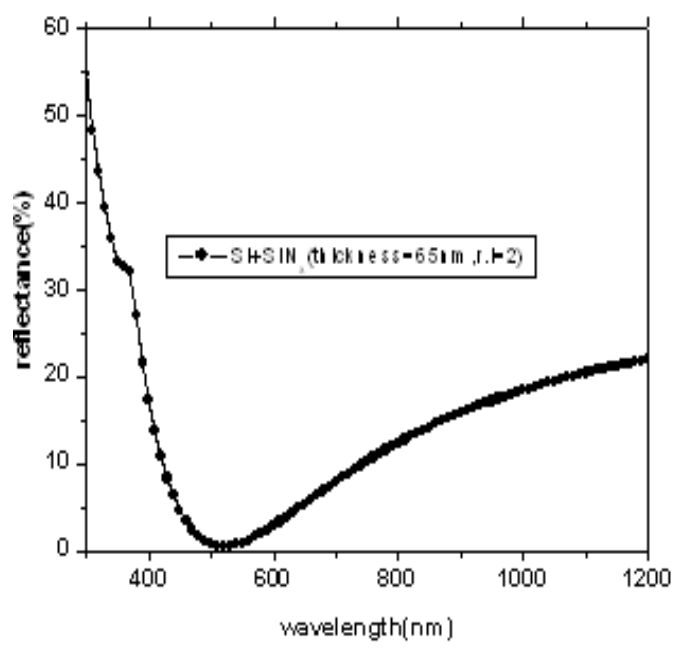

Figure 5. Plot of reflectance versus wavelength for Si+SiNx layer.

\subsection{With Silicon Nitride and Cerium Oxide on Silicon Substrate}

Henceforth, we shall head for the application of cerium oxide along with the single layer of silicon nitride on the the front side of silicon Solar Cell [fig 6].

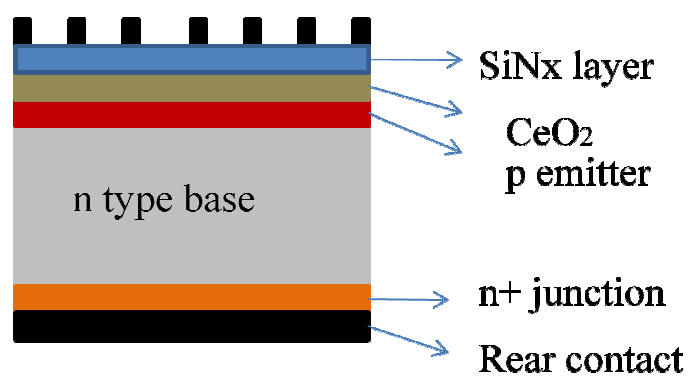

Figure 6. Arrangement of $\mathrm{CeO}_{2}+\mathrm{SiNx}$ layer on Si substrate

As the dielectric constant of $\mathrm{CeO}_{2}$ is higher than $\mathrm{SiNx}$ layer so we have to use this $\mathrm{CeO}_{2}$ layer in between the $\mathrm{SiNx}$ and the emitter surface of c-Si Solar Cell. After the introduction of $\mathrm{CeO}_{2}$ in the Solar Cell it has been found that the efficiency rises than the previous condition i.e the efficiency of $\mathrm{Si}+\mathrm{SiNx}$ combination.. The characteristic table after introducing $\mathrm{CeO}_{2}$ is shown in table 2 .

Table2. Simulated parameters for crystalline silicon structured with $\mathrm{Si}+\mathrm{CeO}_{2}+\mathrm{SiNx}$ layers.

\begin{tabular}{ccccccc}
\hline $\begin{array}{c}\mathrm{CeO}_{2} \\
\text { thickness } \\
(\mathbf{n m})\end{array}$ & $\begin{array}{c}\mathrm{SiNx} \\
\text { thickness } \\
(\mathbf{n m})\end{array}$ & $\mathrm{CeO}_{2}$ r.i & SiNx r.i & $\begin{array}{c}\text { Voc } \\
(\mathbf{V})\end{array}$ & $\begin{array}{c}\mathbf{I}_{\text {sc }} \\
(\mathbf{A})\end{array}$ & $\begin{array}{c}\text { Efficiency } \\
(\%)\end{array}$ \\
\hline 5 & 75 & 2.352 & 2 & 0.617 & 3.37 & 17.30 \\
5 & 60 & 2.352 & 2 & 0.617 & 3.34 & 17.17 \\
10 & 65 & 2.352 & 2 & 0.617 & 3.38 & 17.34 \\
10 & 65 & 2.78 & 2 & 0.617 & 3.37 & 17.31 \\
\hline
\end{tabular}

\subsubsection{Variation of Short Circuit Current Density Versus Open Circuit Voltage}

Fig.7 shows the relevant plots of short circuit current density versus open circuit voltage of the specified layer of solar cell material, while varying the thickness of $\mathrm{CeO}_{2}$ from $5-10 \mathrm{~nm}$ and that of SiNx from $60-75 \mathrm{~nm}$, and the $\mathrm{CeO}_{2}$ refractive index (r.i) between 2.352-2.78.

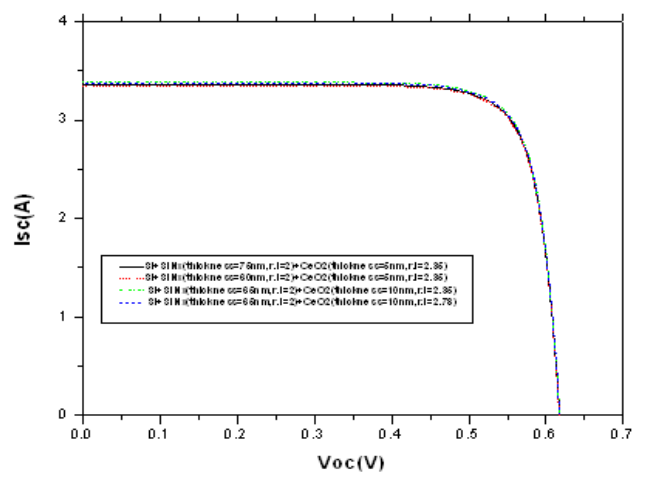

Figure 7. Variation of short circuit current density versus open circuit voltage. 
From the curve we have seen that at $\mathrm{CeO}_{2}$ thickness $10 \mathrm{~nm}$ with r.i 2.352 and SiNx thickness $65 \mathrm{~nm}$ with r.i 2 the maximum efficiency have been found which is $17.34 \%$.

\subsubsection{Variation of Quantum Efficiency Versus Wave- length}

In the next plot, quantum efficiency is made to vary with a spectrum of wavelength values, keeping the same conditions, i.e, $\mathrm{CeO}_{2}$ thickness varying from 5 to $10 \mathrm{~nm}, \mathrm{CeO}_{2}$ r.i varying from 2.352 to $2.78 \mathrm{~nm}, \mathrm{SiN}_{\mathrm{x}}$ thickness varying from 60 to $75 \mathrm{~nm}$, and lastly, $\mathrm{SiN}_{\mathrm{x}}$ r.i being kept constant at 2.00 [Fig.8].

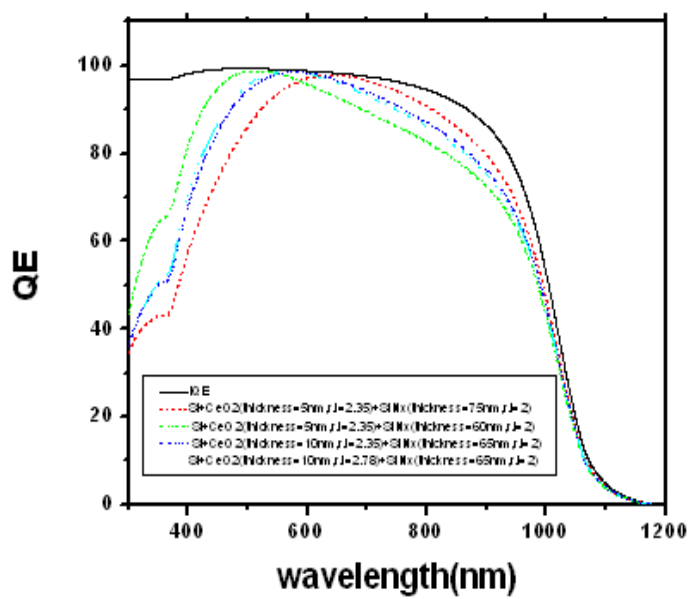

Figure 8.Variation of quantum efficiency versus wavelength under specified conditions

From the different EQE curves that have been obtained under the varying conditions, the one which has maintained the desirable flat topography to some extent has been considered. This is provided by the curve under the condition $\mathrm{Si}+\mathrm{SiNx}$ thickness $=65 \mathrm{~nm}, \mathrm{CeO} 2$ thickness $=10 \mathrm{~nm}$, and $\mathrm{CeO} 2 \mathrm{r} . \mathrm{i}=2.352$. For this curve, the difference between $\mathrm{IQE}$ and $\mathrm{EQE}$ values is the minimum.

It is to be observed over here, that the EQE for the curve we have chosen as optimum has maintained the desirable value throughout. This is possible if and only if, recombination losses have been reduced to a state, which has been impossible to achieve through the combination of $\mathrm{Si}+\mathrm{SiNx}$ only [11]. Thus it is inferred that for this optimum condition, more number of incident photons are trapped, and therefore, the generation rate is also higher.

\subsubsection{Variation of Reflectance Versus Wavelength}

Fig.9 shows the plot between reflectance and wavelength of the $\mathrm{Si}+\mathrm{SiNx}+\mathrm{CeO} 2$ layer. At first it should be mentioned that for all the simulations performed with $\mathrm{Si}+\mathrm{SiNx}+\mathrm{CeO} 2$, the $\mathrm{CeO} 2$ layer thickness is varied from 5 to $10 \mathrm{~nm}, \mathrm{CeO} 2$ r.i from 2.352 to 2.78 , SiNx thickness from $60-75 \mathrm{~nm}$, and SiNx refractive index fixed at 2.00.

For each of the above curves, we have found that they attain a minimum value of reflectance at some point. Now, due to the presence of $\mathrm{CeO}_{2}$, the absorption becomes favorably reduced.Thus the average transmission value is high. Hence more amount of the incident solar radiation is able to penetrate the $\mathrm{SiNx}+\mathrm{CeO}_{2}$ layer and reach the $\mathrm{Si}$ substrate. Consequently, more number of electron-hole pairs is generated at the junction, thereby increasing the generation rate of $\mathrm{Si}$ itself. Hence, it is concluded, that highest efficiency (nearly $=17.34 \%$ in this case) is attained at lowest reflectance.

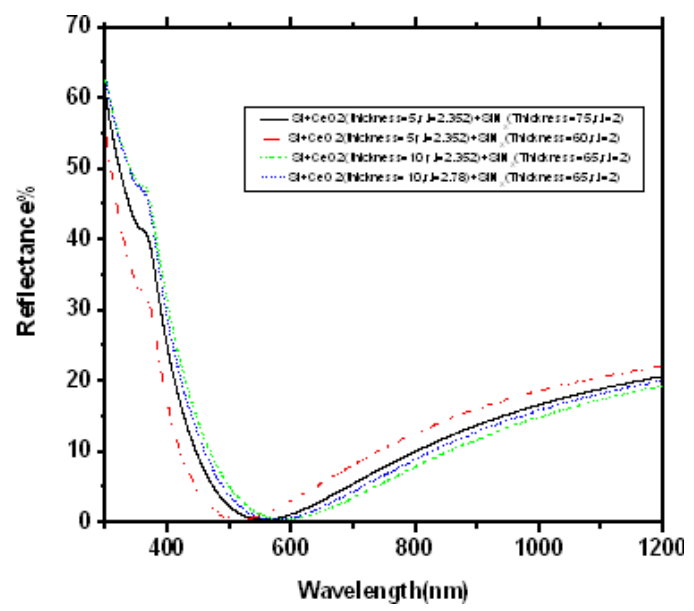

Figure 9. Variation between reflectance and wavelength of $\mathrm{Si}+\mathrm{SiNx}+\mathrm{CeO}_{2}$ layer.

\section{Conclusion}

Through the simulation works it has been established that some inevitable benefits are obviated when $\mathrm{CeO}_{2}$ is introduced along with Silicon Nitride. The reflectance curves are allowed to have a range of wavelength values where they can attain minimum reflectance. By using $\mathrm{SiNx}+\mathrm{CeO}_{2}$ layer, we have obtained reflectance curves which individually attain minimum values at certain points, thereby enabling us to obtain an average value of reflectance, for which desirable transmission will take place.

The quantum efficiency curves pave way for selecting the most appropriate curve where the desirable topography of EQE and IQE curves are maintained. In case of the plots taken for only $\mathrm{SiN}_{\mathrm{x}}$ layer, we find that the deviations between EQE and IQE curves are quite high, which is not desirable. But in case of the plots taken for $\mathrm{SiN}_{\mathrm{x}}+\mathrm{CeO}_{2}$, it is found that for a particular condition, i.e, $\mathrm{Si}+\mathrm{SiN}_{\mathrm{x}}$ thickness $=65 \mathrm{~nm}, \mathrm{SiNx}$ r.i. $=2, \mathrm{CeO}_{2}$ thickness $=10 \mathrm{~nm}$, and $\mathrm{CeO}_{2} \mathrm{r} . \mathrm{i}=2.35$, the EQE curve has maintained a minimum deviation from the IQE curve.

Here an ideal Solar cell has been taken for the simulation purpose. But to actuate an as high value of efficiency for a practical solar cell, we must take adequate measures by the proper utilization of dielectrics like $\mathrm{CeO}_{2}$, so that the reflectance losses can be reduced to some feasible extent of the Solar Cell.

\section{Acknowledgements}

The authors deeply acknowledge Meghnad Saha Institute of Technology, TIG provides the infrastructural support for carrying out research activity in this area. The authors also 
gratefully to acknowledge the DST, Govt. of India for financial support for carrying out solar cell related research activity.

\section{References}

[1] Y.S. Tsuo, T.H. Wang, and T.F. Ciszek, "Crystalline-Silicon Solar Cells for the 21st Century", Conference: Preceedings of "the Electrochemical Society Annual Meeting(1999)" NREL report no. CP-590-26513, Vol. 99-11.pp. pp. 49-56..

[2] R. Brendel,S. Dreissigacker,N.-P. Harder,and P. P. Altermatt, "Theory of analyzing free energy losses in solar cells “,Applied Physics Letters(2008) , Vol. 93, pp.173503 173503-3.

[3] M.F. Stuckings, A.W. Blakers " A study of shading and resistive loss from the finngers of encapsulated solar cells" Solar Energy Materials and Solar Cells(1999), Vol. 59, Pages 233-242.

[4] U.Gangopadhyay, S. Roy, S.Garain, S. Jana, S.Das "Comparative simulation study between n- type and p- type Silicon Solar Cells and the variation of efficiency of n- type So- lar Cell by the application of passivation layer with different thickness using AFORS HET and PC1D" IOSR Journal of Engineering (IOSRJEN) ISSN: 2250-3021 Vol. 2, ,August 2011, pp 41-48.

[5] Michael M. Tilleman ; Dan Haronian ; David Abraham, "Thickness of silicon-nitride antireflective coating on a silicon waveguide measured by an integrated micromechanical gauge" Journal of Micro/Nanolithography, MEMS, and MOEMS(2006), Vol. 5 ,pp-023011.

[6] J. T. Jones,E. T. Croke,C. M. Garland,O. J. Marsh, and T. C. McGil, "Epitaxial silicon grown on $\mathrm{CeO} 2 / \mathrm{Si} 111$ structure by molecular beam epitaxy", ournal of Vacuum Science and Technology, vol-16,pp- 2686-2689.

[7] G. Dingemans and W. M. M. Kessels, "Status and prospects of Al2O3-based surface passivation schemes for silicon solar cells", Journal of Vacuum Science \& Technology(2012),Vol-30,pp-040802.

[8] Chun-Heng Chen, Ingram Yin-Ku Chang, Joseph ya-Min Lee and Fu-Chien Chiu, "Electrical characterization of $\mathrm{CeO} 2 / \mathrm{Si}$ interface properties of metal oxide semiconductor field effect transistor with $\mathrm{CeO} 2$ gate dielectric.Applied Physics Journal 2008,Vol-92,pp-043507. 